\title{
Experiências na formação de psicoterapeutas antirracistas
}

\author{
Experiences in training anti-racist psychotherapists
}

\section{Virginia Teles Carneiro}

Resumo: Partindo da premissa de que as questões raciais são estruturantes para a construção da sociedade brasileira e que, como tal, marcam profundamente as perspectivas epistemológicas mais usualmente utilizadas na psicologia, o texto tem como objetivo relatar experiências na formação de psicoterapeutas na qual o antirracismo foi abordado como uma atitude fundamental para a prática clínica. Os estágios supervisionados aconteceram no último ano do curso de graduação em Psicologia de uma universidade pública. A partir da escuta de mulheres negras e periféricas que tinham o racismo como fonte de seus sofrimentos psíquicos, cinco estagiárias sentiram-se impelidas a redimensionar suas posturas clínicas. Apontam-se possibilidades de sistematização para incluir o antirracismo na formação do psicoterapeuta, como o desenvolvimento da identidade racial do supervisor e dos estagiários e, no caso de pessoas brancas, conhecer sobre branquitude. A produção deste texto intenciona fornecer subsídios para o desenvolvimento de outras iniciativas relativas à formação de psicoterapeutas, visando a construção de uma clínica psicológica antirracista localizada geopoliticamente na realidade brasileira.

Palavras-chave: Racismo; Psicoterapia; Formação do psicólogo.

\begin{abstract}
Starting from the premise that racial issues are structuring for the construction of Brazilian society and that, as such, it deeply marks the epistemological perspectives most commonly used in psychology, the text aims to report experiences in the training of psychotherapists in which anti-racism was addressed as a fundamental attitude for clinical practice. The supervised internships took place in the final year of the undergraduate Psychology course at a public university. From listening to black and peripheral women who had racism as a source of their psychic suffering, five interns felt impelled to redimension their clinical postures. Possibilities of systematization are pointed out to include anti-racism in the psychotherapist's training, such as the development of the supervisor's and interns' racial identity and, in the case of white people, knowing about whiteness. The production of this text intends to provide subsidies for the development of other initiatives related to the formation of psychotherapists, aiming at the construction of an anti-racist psychological clinic located geopolitically in the Brazilian reality.
\end{abstract}

Keywords: Racism; Psychotherapy; Psychologist training.

\footnotetext{
1 Psicóloga. Doutora em Psicologia pela Universidade Federal da Bahia. Professora Associada I da Universidade Federal de Campina Grande. E-mail: virginiateles@gmail.com
} 


\section{Introdução}

Como se desenvolve uma escuta clínica? Quais são os atributos essenciais de um psicoterapeuta? Quais são os elementos primordiais necessários para a formação de um psicoterapeuta, aqueles sem os quais poderíamos afirmar que a formação é deficitária? Embora não existam respostas consensuais para essas perguntas, questionamentos como esses têm direcionado há décadas o trabalho de docentes que atuam como orientadores de estágio supervisionado no campo da psicologia clínica. A formalização freudiana lançada no início do século XX sobre a formação do psicanalista, composta pela análise pessoal, supervisão clínica e estudo teórico, permeia até os dias atuais o que se considera como metodologia básica para a formação do psicólogo clínico, com as devidas atualizações e adaptações a diferentes perspectivas teóricas e contextos institucionais. Embora existam pesquisas em outros países que apontem características gerais do psicoterapeuta na direção de uma maior expertise (Corbella \& Botella, 2004, Corbella, 2019), não é comum que esses elementos façam parte da rotina formativa nas mais diferentes instituições.

Sendo a área preferida pelos aspirantes a psicólogo, a psicologia clínica está em constante tensionamento em relação a que concepções de mudanças sociais ela corresponde. Desde que o psicólogo se inseriu nos serviços públicos de saúde por volta da década de 1970, discutem-se possibilidades para uma atuação quevá além do atendimento clínico individual embasado na lógica privatista e que seja contextualizada de acordo com a realidade da comunidade em que está inserido (Cintra \& Bernardo, 2017). Porém, também na modalidade da psicoterapia temos certa dificuldade em encontrar literatura que aborde quais são os desdobramentos práticos acerca de um posicionamento clínico que considere o contexto de vida daquele que está demandando cuidado. A psicoterapia é polissêmica e há uma diversidade de abordagens teóricas que norteiam 0 atendimento psicológico, a partir das quais o próprio significado da expressão"contextualização" pode variar. Embora sejam múltiplas, essas teorias têm algo em comum ao se pensar a realidade brasileira: foram criadas por autores e autoras que viveram em outra época e condições geopolíticas, dado que, em geral, são originários(as) do hemisfério norte, normalmente Estados Unidos e países da Europa.

Para situar a prática psicoterápica geopoliticamente, é incontornável desnudar que desde sua regulamentação no país ela jamais foi originalmente brasileira. A recente disseminação do pensamento decolonial tem possibilitado a reflexão acerca de nossas escolhas teóricas numa direção que vai muito além de atualizações para demandas atuais, direcionando o olhar para as bases que possibilitaram que certas ideias tenham ganhado legitimidade, sendo concebidas como um prisma sob o qual se pode certamente compreender o ser humano e igualmente propor modelos para os mais variados tipos de intervenção. Mignolo (2014), um dos autores do pensamento decolonial latino-americano, define colonialidade como uma "'matriz ou padrão colonial de poder', a qual é um complexo de relações que se esconde detrás da retórica da modernidade (o relato da salvação, progresso e felicidade) que justifica a violência da colonialidade" (p. 13).

É no contexto da conquista das Américas no século XVI que se conjugam formas de dominação e subordinação que foram centrais para justificar 0 controle sobre os sujeitos colonizados. De acordo com Almeida (2018), nesse contexto, a invenção da ideia de raça foi fundamental para codificar a diferença entre conquistadores e conquistados. Essa suposta estrutura biológica natural serviu para classificar os humanos entre superiores e inferiores, elemento fundamental e constitutivo das relações de dominação impostas na obtenção do que foi denominado de América.
0 racismo é um princípio constitutivo que organiza, a partir de dentro, todas as relações de dominaçãa da modernidade, desde a divisão internacional do trabalho até as hierarquias epistêmicas, sexuais, de gênero, religiosas, pedagógicas, médicas, junto com as identidades e subjetividades, de tal maneira que divide tudo entre as formas e os seres superiores (civilizados, hiper-humanizados, etc., acima da linha do humano) e outras formas e seres inferiores (selvagens, bárbaros, desumanizados, etc., abaixo da linha do humano) (Grosfoguel, 2020, p. 59).

Seguindo essa lógica, as várias dimensões que envolvem os processos de construção do conhecimento reproduzem violências e conservam hierarquias que privilegiam pessoas brancas. Kilomba (2019), ao questionar quem é autorizado a falar, discute maneiras de silenciar e negar a escuta a pessoas negras, propondo uma descolonização daquele conhecimento que se coloca como universal: "A ciência não é um simples estudo apolítico da verdade, mas a reprodução de relações raciais de poder que ditam o que deve ser considerado verdadeiro e em quem acredita" (p. 53-54). Em um país que teve a discussão postergada em virtude do mito da democracia racial, especialmente no que se refere à população negra, é de se esperar que a psicologia, assim como outras áreas de conhecimento, tenha se ausentado do aprofundamento das investigações sobre relações raciais. Sue, Sue, Neville e Smith (2019) afirmam que os valores da classe média branca frequentemente estão refletidos nas pesquisas psicológicas, que reproduzem a cultura da população branca para a população branca como se fossem teorias de aplicação universal.

Historicamente, é na psicologia social em que se concentra a produção de conhecimento sobre relações raciais e racismo (Sacco, Couto \& Koller, 2016). № âmbito da psicologia clínica, há uma grande lacuna de conhecimento. Tavares e Kuratani (2019, p. 2-3) afirmam que na psicologia clínica brasileira," não se tem um corpo de conhecimentos, métodos ou estratégias sistematicamente desenvolvidas para o manejo clínico das repercussões do racismo sobre a saúde mental da população negra". Isso corrobora os achados de Gouveia e Zanello $(2018$, p. 3) que investigaram a produção brasileira indexada na área de racismo e saúde mental entre os anos de 1999 e 2014 e concluem que "a maior parte da produção é da psicologia social, sendo praticamente nula a produção na área clínica, e não aparece intercâmbio entre as duas áreas".

Esse silenciamento é reflexo do racismo antinegro profundamente incrustado em nossa sociedade, pois intelectuais negras há muito tempo já sinalizavam para a importância do sofrimento psíquico da população negra, a exemplo de Virgínia Bicudo, que foi pioneira nos estudos raciais no campo clínico, tendo realizado sua dissertação de mestrado na década de 1940 e Neusa Santos Souza, que numa ótica psicanalítica procura compreender as trajetórias pessoais no processo de ascensão social de pessoas negras numa sociedade embranquecida (Bicudo, 1947; Souza, 1990). Assim, apesar de 56,4\% da população brasileira ser formada por pessoas negras (IBGE, 2020), na psicologia clínica tradicionalmente importamos teorias psicológicas europeias e norte-americanas pensadas por pessoas brancas, normalmente homens, para discutir a construção da subjetividade, o sofrimento psíquico, 0 adoecimento mental e as diversas formas de intervenção terapêutica. Consequentemente, sorrateiramente, o racismo estrutural e institucional (Almeida, 2018) marca profundamente a formação do psicoterapeuta. É muito importante destacar que reconhecer isso não significa anular todo esse 
conhecimento já produzido em outros continentes, mas sim estabelecer uma relação fronteiriça de desprendimento com os modos de ser e saber impostos, como afirmado por Mignolo (2014, p. 15): a "descolonialidade não consiste em um novo universal que se apresenta como verdadeiro, superando todos os previamente existentes".

A partir do reconhecimento de que o racismo antinegro é inerente aos processos de subjetivação contemporâneos e que de maneira até então inevitável está presente em grande parte das teorias e práticas psicológicas, 0 presente texto tem como objetivo relatar experiências em orientação de estágio supervisionado, voltado para a formação de psicoterapeutas, na qual 0 antirracismo foi abordado como uma atitude fundamental do psicólogo clínico. É importante aqui destacar o antirracismo como básico e indispensável para o exercício da psicoterapia, ou seja, não é uma habilidade especial a ser desenvolvida apenas para aqueles que atendem grupos conhecidos como minoritários, pois raça, cor, etnia e cultura participam da construção de subjetividade de todos, não apenas de grupos historicamente oprimidos. Pelo fato de a cultura branca ser dominante e não se perceber em termos raciais, ou seja, é entendida como padrão normativo (Diangelo, 2018), ela obscurece a visão de que nas teorias e práticas psicoterapêuticas há um sistema potencialmente tendencioso a um monoculturalismo. Sue et al. (2019), importantes pesquisadores no campo do Aconselhamento Multicultural, trazem elementos que podem perfeitamente ser articulados com a psicoterapia. Os autores afirmam a necessidade de que os conselheiros se tornem culturalmente cientes, para que possam, assim, agir com base em uma análise crítica e compreensiva de seus próprios condicionantes, bem como de seus clientes, englobando o sistema sócio político do qual ambos fazem parte. Sem tal consciência, o conselheiro que trabalha com uma cultura diferente do cliente pode estar envolvido na opressão cultural usando métodos antiéticos e práticas prejudiciais, que beira uma violação dos direitos humanos. Partindo dessas considerações e também do fato de que no Brasil já existe uma regulamentação (Resolução no 18/ 2002) que estabelece normas de atuação para os psicólogos em relação ao preconceito e à discriminação racial (Conselho Federal de Psicologia, 2002), a produção deste texto intenciona fornecer subsídios para o desenvolvimento de outras iniciativas relativas à formação de psicoterapeutas, visando a construção de uma clínica psicológica localizada geopoliticamente na realidade brasileira e comprometida em retificar a produção de iniquidades históricas promovidas com a participação de teorias e práticas psicológicas.

\section{Método}

Sistematizar o percurso percorrido na formação de psicoterapeutas antirracistas é desafiador, pois o antirracismo não é algo palpável, com contornos nitidamente definidos e com uma clara linha de chegada a ser alcançada. Se o racismo é multiforme e está em constante atualização, 0 antirracismo precisa acompanhar esse movimento. As experiências em estágio supervisionado específico aqui descritas aconteceram no último ano do curso de graduação em Psicologia de uma universidade pública, com 05 estudantes distribuídas em três diferentes turmas, que escolheram fazer o estágio na ênfase clínica, tendo como norteador teórico principal a Abordagem Centrada na Pessoa $(A C P)$, desenvolvida pelo norte-americano Carl Rogers e amplamente difundida no Brasil.

A orientação teórico-prática, que denominaremos a partir de agora como supervisão, aconteceu em grupo, em turmas separadas com no máximo seis estudantes, uma vez por semana, com duração aproximada de quatro horas. Os atendimentos clínicos e as supervisões foram realizados no Serviço Escola de Psicologia da instituição, que fica localizado dentro da universidade e em um bairro geograficamente periférico da cidade. Todas as atividades oferecidas no Serviço são gratuitas. Para evitar uma longa fila de espera, as vagas para psicoterapia são abertas periodicamente, com ampla divulgação. A pessoa interessada deve espontaneamente ir à instituição e participar de uma entrevista de triagem. Nessa entrevista é preenchida uma ficha que contém dados sobre a caracterização sociodemográfica, histórico de atendimentos anteriores e motivos para procurar a psicoterapia. 0 atendimento é aberto a toda população, mas há preferência para pessoas de baixa renda e em situações avaliadas como urgentes. Em relação ao perfil dos usuários, a grande maioria é composta por mulheres, pouco mais da metade do total de pessoas que procuram psicoterapia é formada por estudantes universitários, sendo o restante pertencente à comunidade em geral.

As discussões sobre racismo em supervisão iniciaram quando a temática começou a aparecer com mais frequência nas sessões de psicoterapia. Portanto, a proposição declarada de um posicionamento antirracista para 0 psicoterapeuta não foi algo planejado, pois foi resultado dos impactos provocados pelas verbalizações de mulheres negras e periféricas em sessões de psicoterapia. Foram essas mulheres, usuárias do Serviço Escola, que trouxeram o tema à tona e o colocaram como fundamental para se repensar a formação do psicoterapeuta, o que foi acolhido como uma mudança de paradigma urgente nas ações clínicas de até então. A experiência a ser relatada refere-se ao atendimento de mulheres autodeclaradas negras, com idade entre $18 \mathrm{e}$ 30 anos, e em processo de construção de suas identidades raciais. Elas foram atendidas por cinco estagiárias, também mulheres, com idades entre 22 e 30 anos, das quais uma se reconhecia como negra e quatro como brancas. Embora seja de conhecimento da autora que a partir de uma ótica interseccional gênero, raça e classe não se separam, o foco será nas relações raciais.

\section{Discussão}

Para conduzir o presente relato, utilizou-se como base as ideias defendidas por Sue et al. (2019), que delinearam as características do terapeuta culturalmente competente ao longo de três dimensões, que estão intrinsecamente articuladas: a) estar ativamente consciente de sua própria visão de mundo como resultante de uma cultura e como isso pode refletir em sua prática, especialmente com as chamadas minorias raciais e étnicas; b) buscar compreender a visão de mundo de seu cliente culturalmente diferente com apreço e respeito, sem julgamentos negativos e repetições de estereótipos; c) sensibilidade para adequar suas intervenções de acordo com as experiências de vida e valores culturais dos clientes. Os autores afirmam que o processo de desenvolvimento da competência multicultural é ativo e contínuo, pois não há como alcançar um ponto final diante da complexidade e diversidade dos diferentes públicos, das transformações sociais, bem como do reconhecimento das limitações pessoais do conselheiro, havendo sempre a necessidade de mudanças em direção a um atendimento mais qualificado.

As vivências descritas a seguir não ocorreram simultaneamente e dentro de um mesmo grupo de estágio. 0 sofrimento psíquico relacionado ao racismo começou a tornar-se um tema repetitivo nas supervisões em meados de 2018. 0 clima político no país naquele ano eleitoral fez com que muitos debates acerca de nossa realidade social adentrassem nas sessões de psicoterapia, 0 que se manteve nos anos seguintes. Mulheres negras, jovens e periféricas passaram a falar explicitamente sobre o racismo e suas consequências em 
suas vidas pessoais, o que denota um certo movimento anterior e exterior ao início da psicoterapia, em direção a construção de suas identidades.

Seguindo as dimensões propostas por Sue et al. (2019), na supervisão foi preciso atentar para a compreensão de si e de racismo das estagiárias, pois sem dúvida isso teria influência nas relações estabelecidas com as clientes. Para facilitar o entendimento do leitor, cada estagiária será denominada por uma letra ( $A, B, C, D$ e E). A forma como cada estagiária relatou em supervisão a vivência ao se deparar com o tema racismo no atendimento apontou para dois elementos importantes: como elas se reconheciam em relação à própria raça e o nivel de conhecimento teórico sobre relações raciais, racismo e sofrimento psíquico da população negra. Ficou claro que dentre as estagiárias, duas delas (A e B), autodeclaradas brancas, estavam alienadas de suas próprias identidades raciais, diferentemente das estagiárias C, D e E, que demonstraram algum conhecimento sobre como se identificavam em relação a própria raça e o significado disso em nossa sociedade. As estagiárias C e D reconheciam-se como brancas e a estagiária E como negra.

Esse reconhecimento de si trouxe consequências para os atendimentos. As estagiárias A e B reproduziam uma ideia típica da branquitude: "quem tem raça é o negro". Schucman (2020) afirma que na base dos estudos atuais sobre identidade racial branca está a branquitude, definida como uma posição ocupada por sujeitos sistematicamente privilegiados em relação ao acesso a recursos materiais e simbólicos que foram gerados inicialmente pelo colonialismo e pelo imperialismo, e que se mantêm e são preservados. Para a autora, é importante ressaltar que ocupar o lugar simbólico de branquitude depende do entrecruzamento de diferentes categorias sociológicas como etnia, cor, cultura e raça, que são concebidas de forma diversa a depender da região, história, época e interesses políticos. Dessa forma, branquitude não pode ser definida a partir apenas da cor da pele. Frankenberg (2004) aponta para a multidimensionalidade da branquitude, como uma ótica a partir da qual os brancos olham para si mesmos, para os outros, para várias práticas culturais não nomeadas e para a sociedade como um todo. Afirma que uma das premissas fundamentais da branquitude é a definição dos brancos como o padrão universal para os humanos, enquanto que as pessoas não brancas seriam um desvio dessa norma.

Sendo a raça branca invisibilizada, comumente os temas relacionados a raça e racismo no Brasil se referem à negritude, com o branco excluindo-se do debate. Esse não reconhecimento gera uma proteção ao branco de lidar com essas questões. Diangelo (2018. p. 24, grifos da autora) afirma que "a menor dose de estresse racial é intolerável, frequentemente, a simples sugestão de que ser branco tem um significado faz disparar uma gama de respostas defensivas. [...] Classifico esse processo como fragilidade branca". As defesas podem apresentar-se de diferentes formas, como raiva, medo, culpa, silêncio, etc., mas sempre com o objetivo de restaurar o conforto racial, livrando-se do desconforto e ansiedade e mantendo protegidas as vantagens brancas.

A princípio, quando as clientes traziam à tona a temática do racismo, as estagiárias A e B não sentiam desconforto racial, pois não conseguiam perceberem a si mesmas nessa estrutura. Foi durante os atendimentos que elas descobriram que a cor da pele delas tinha impacto na relação terapêutica, a partir de verbalizações das próprias clientes, que abertamente demonstraram incômodo e desconfiança em falar sobre seus sofrimentos relacionados ao racismo para pessoas brancas. Estudos apontam que o pertencimento a determinado grupo étnico é um fator a ser considerado para a construção da aliança terapêutica. Corbella e Botella (2004) consideram que fatores como grupo étnico, gênero e idade são relevantes, mas não há um perfil demográfico específico que possa ser generalizado. "Todavia, a combinação com as necessidades do paciente é que torna o gênero, a idade ou a etnia do terapeuta um possível indicador de resultados da terapia" (p. 128). No caso de uma díade interracial na qual o cliente é negro e o terapeuta branco, há estudos que afirmam que os clientes podem direcionar sua raiva para os terapeutas, pois eles simbolizam a cultura dominante, porém, o relacionamento interracial por si não anula a possibilidade de construir uma boa vinculação, pois há outros fatores que podem contribuir para uma boa aliança terapêutica (Tavares \& Kuratani, 2019).

Como 0 processo de construção da própria identidade racial é muito singular, o modo de abordar isso em supervisão com as estagiárias foi se dando também de modo singular. Para isso, foi fundamental que a supervisora tivesse consciência de sua própria identidade racial e sobre seu nível de conhecimento a partir de estudos sobre raça e racismo, especialmente no que se refere à branquitude, visto reconhecer-se como branca. Foi necessário sensibilidade para facilitar o entendimento das estagiárias como seres raciais e culturais na direção de uma construção de identidade antirracista. Além disso, era preciso estar atenta ao que Bento (2002) chamou de pacto narcísico da branquitude e Diangelo denominou de solidariedade branca (2018), que seriam acordos tácitos para manutenção do privilégio branco. Através do silenciamento e da invisibilização do papel das pessoas brancas para a perpetuação do racismo, brancos protegem a vantagem branca e tentam não causar desconforto racial a outro branco se eles forem confrontados diante de uma atitude racista. Trazer à tona 0 antirracismo significa necessariamente romper com esses acordos tácitos, porém, éinegável que foi a existência deles que facilitou a escuta inicial das estagiárias A e B sobre o que era trabalhado em termos de relações raciais, pelo fato de a supervisora também se reconhecer como branca.

As estagiárias A e B se sentiram bastante impactadas após as sessões em que foram confrontadas pelas clientes, como se naquele momento tivesse se desnudado para elas o que significava serem brancas numa sociedade marcada pelo racismo antinegro. Isso proporcionou pontos de mudança nos atendimentos, com uma grande diferença entre eles. A estagiária A começou a refletir sobre seu desconforto racial branco, o que foi muito facilitador para o estreitamento do vínculo terapêutico e continuidade dos atendimentos com uma cliente que trazia constantemente a temática do racismo para as sessões. Em supervisão, pudemos discutir em grupo (o que foi formativo para todos os estagiários presentes) que a sensação de uma compreensão empática limitada identificada pela estagiária estava diretamente relacionada ao desconforto gerado por uma díade interracial. A palavra empatia tem sido amplamente utilizada no senso comum, mas na ACP a compreensão empática tem suas especificidades teórico-práticas, estando entre os fundamentos da abordagem. Inicialmente definida por Rogers como um estado e uma habilidade que deve partir do terapeuta, o conceito foi se modificando e a empatia passou a ser elaborada como compreensão empática e um processo que acontece entre terapeuta e cliente (Moreira \& Torres, 2013). Para Rogers (1985), a compreensão empática acontece "quando o terapeuta é sensível aos sentimentos e às significações pessoais que o cliente vivencia a cada momento, [...] e quando consegue comunicar com êxito alguma coisa dessa compreensão ao paciente" (p.72).

Foi esclarecedor entender que a desconfiança da cliente e a sua dificuldade de "entrega"em psicoterapia, percebidas desde o início pela estagiária A, não se dava necessariamente por fatores psíquicos não conscientes que poderiam resultar em uma suposta resistência, mas sim pelo nível de entendimento 
consciente da cliente acerca de sua própria identidade racial e pela clareza do que significava para ela relatar para uma pessoa branca não racializada aspectos de seu sofrimento relacionado ao racismo. Gomes (2019) traz uma interessante reflexão acerca disto, ao dissertar sobre os limites da empatia na escuta das mulheres negras: "é mais provável acontecer uma experiência de compreensão empática quando as pessoas envolvidas dispõem de um universo minimamente comum" (p. 42). A autora resgata uma afirmação de Wood et al. (1994), importante referência da ACP, quando ele afirma que"a experiência de compreensão empática é também uma função cultural" (p. 232), pois 0 terapeuta dispõe de seu próprio self, sua experiência pessoal e seu universo de significados, além de sua competência técnica, para compreender empaticamente al guém. Isso quer dizer que numa díade interracial na qual o terapeuta seja branco e o cliente negro, é possível haver aliança terapêutica, mas se 0 terapeuta ignora questões multiculturais importantes para a situação, o cliente poderá sentir-se incompreendido, mesmo que o terapeuta se disponha a compreendê-lo empaticamente. De acordo com Wood et al. (1994, grifos do autor), na perspectiva da ACP, não é suficiente apenas tentar compreender 0 mundo do outro, pois o cliente também deve experienciar ser compreendido, ou seja, o terapeuta deve "facilitar o fenômeno da compreensão empática" (p.234). Um terapeuta bem intencionado e alienado de sua identidade racial pode reproduzir o racismo antinegro, pois o racismo como algo que estrutura a sociedade e tem impacto na construção das subjetividades, independe da intenção individual para se materializar. Essa mudança no entendimento acerca da compreensão empática é, sem dúvida, uma tentativa de adequação da intervenção que considera experiências de vida e valores culturais do cliente, como sugerido por Sue et al. (2019). É também o reconhecimento de possíveis limitações da capacidade empática do psicoterapeuta em certas situações.

De modo bem diferente, a estagiária B não conseguiu lidar com seu desconforto racial, criando estratégias para evitar a confrontação interracial. Verbalizações semelhantes a"não posso compreender o seu sofrimento porque eu sou branca" nitidamente prejudicaram o vínculo terapêutico, de modo que a cliente não deu continuidade aos atendimentos. Nesse momento, a aproximação da estagiária em relação a sua própria identidade racial aflorou sua fragilidade branca (Diangelo, 2018), ao se deparar diretamente com 0 sofrimento psíquico em consequência do racismo relatado pela cliente. Embora isso tenha sido discutido em supervisão, um bom vínculo terapêutico com a cliente não foi estabelecido, provocando a desistência do atendimento. Para a supervisora foi importante verificar que a compreensão sobre a identidade racial branca está intrinsecamente relacionada ao conhecimento sobre as características da branquitude. Assim, mesmo que o estagiário branco demonstre conhecimento sobre relações raciais e se reconheça como branco, é preciso que ele estude sobre branquitude, pois é característica desta identidade a invisibilização de uma cultura própria.

Situações muito diferentes das supracitadas aconteceram com as três estagiárias que tinham maior conhecimento sobre o impacto da diferença ou semelhança na identificação da raça da terapeuta e da cliente, fossem elas brancas ou negras. Embora no Brasil haja uma imensa lacuna de conhecimento acerca das experiências de minorias raciais em psicoterapia, outros países fazem investigações sobre o assunto há décadas. Dentre as temáticas pesquisadas está a correspondência racial, que ocorre quando clientes e psicoterapeutas compartilham a mesma raça. Estudos norte-americanos sugerem que a correspondência racial está associada a menor abandono de tratamento, maior procura por atendimento, maior satisfação e melhores resultados (Gamst et al., 2003; Meyer \& Zane, 2013). De modo geral, clientes de minorias raciais percebem os conselheiros que são semelhantes racialmente como mais confiáveis porque supõem similaridades em relação a cultura e valores, elementos importantes para o vínculo terapêutico Mas é importante destacar que isso não é algo estático, pois as visões de mundo e os estágios de identidade racial de ambos podem ter impacto maior no aconselhamento do que a raça por si só, pois indivíduos com uma identidade racial mais desenvolvida podem dar mais importância à correspondência racial (Ward, 2005; Meyer \& Zane, 2013).

A construção da identidade racial das clientes atendidas pelas estagiárias C, D e E era um fator central em suas demandas. As três estagiárias estabeleceram uma boa aliança terapêutica, pois, de algum modo, atitudes antirracistas foram identificadas pelas clientes, visto que as estagiárias perceberam especialmente através da comunicação não verbal que as clientes sentiam confiança em falar sobre racismo. A cliente da estagiária C, por exemplo, chegou à conclusão que seu adoecimento psíquico (ela já estava em acompanhamento psiquiátrico) tinha relação direta com as agressões sofridas dentro de sua própria família pelo fato de ser negra, sendo a psicoterapia um elemento importante para a supressão dos sintomas. De acordo com o Ministério da Saúde (Brasil, 2016) é inegável que a saúde mental da população não branca é diretamente afetada pelo racismo. Desigualdades nas oportunidades, violência e ameaças à autoestima "são fatores que podem levar a população negra ao sofrimento psíquico, em formas e intensidades diversas" (p. 24). Deste modo, é indispensável que durante a formação do psicoterapeuta ele tenha acesso a estudos que correlacionem racismo e adoecimento psíquico, do contrário essas questões poderão ser tangenciadas e causar ainda mais sofrimento. Em uma sociedade que comumente nega o racismo, a legitimação do sofrimento é um indicador de um posicionamento antirracista do terapeuta (Tavares e Kuratani, 2019), algo que não passou despercebido pelas clientes, sendo facilitador para a aliança terapêutica. No que se refere a estagiária $E$, a única que se reconhecia como negra, havia um impacto positivo imediato nas clientes negras, que chegavam a verbalizar uma surpresa positiva em encontrar "uma pessoa parecida" para atendê-las. Um estudo conduzido por Ward (2005) com clientes afro-americanos identificou que eles relataram avaliar primeiramente a raça do conselheiro, para então avaliarem outras variáveis, como idade e gênero.

Na dinâmica da supervisão, também foi necessário falar sobre a relação interracial entre a supervisora e as estagiárias. Foi de suma importância que a supervisora estivesse investida da construção de sua identidade racial e dos estudos tanto sobre o sofrimento da população negra como sobre a branquitude, para ficar atenta ao surgimento de possíveis pactos narcísicos da branquitude (Bento, 2002), à sua fragilidade branca (Diangelo, 2018) e ao manejo de tensões advindas da diferença racial. Sem essa sensibilidade cultural, por ocupar uma posição de poder, seria capaz de estimular a reprodução do racismo e gerar inseguranças na exploração do tema, trazendo prejuízos significativos para a formação. Inspirada nos ensinamentos de Hooks (2013) acerca de uma pedagogia engajada, em vários momentos a supervisora revelou suas próprias inquietações como uma forma de facilitar que as estagiárias fizessem o mesmo. Para Hooks (2013, p.35), "os professores que esperam que os alunos partilhem narrativas confessionais, mas não estão eles mesmos dispostos a partilhar as suas exercem o poder de maneira potencialmente coercitiva".

Compreender o racismo como estruturante de nossa sociedade significa assumir que ele independe das intenções individuais para existir, inclusive numa relação terapêutica. Neste sentido, para ter uma postura coerente com a eliminação de práticas discriminatórias negativas, ou seja, antirracista, 0 
psicoterapeuta precisa desde sua formação desenvolver sensibilidade para questões que envolvem diferentes opressões em nosso meio social, pois, como já dito anteriormente, uma das dimensões da manutenção do racismo se dá no campo pedagógico, visto que a psicologia historicamente tem reproduzido a colonialidade ao se fundamentar na população branca. Entendendo que suas ações também são resultado de sua cultura, o psicoterapeuta poderá amenizar possíveis impactos negativos e ter uma atuação mais precisa e qualificada.

\section{Considerações finais}

A inclusão do antirracismo como uma atitude clínica fundamental na formação do psicoterapeuta se deu de forma processual e não planejada, a partir da escuta de mulheres negras e periféricas, que convocou uma mudança no que era praticado até então. Os elementos destacados na tradução desta experiência em escrita apontam para possibilidades de uma sistematização que pode ser utilizada em supervisão, independente da abordagem teórica norteadora. 0 ponto inicial refere-se à construção da própria identidade racial do supervisor e dos estagiários. É preciso que eles compreendam os significados sociais de suas raças e os impactos disso no âmbito das relações humanas. Essa reflexão de si precisa vir acompanhada de estudos teóricos que situem geopoliticamente o racismo no Brasil. Não é possível propor uma formação antirracista se professores não forem, eles mesmos, antirracistas.

No caso de o supervisor identificar-se como branco, é imprescindível conhecer as características da branquitude, pois sem isso ele pode facilmente tentar escapar de seu desconforto racial, deixando emergir emoções e comportamentos racistas. Caso ele tenha conhecimento sobre o sofrimento psíquico da população negra, mas não se perceba como parte do que pode promover esse sofrimento, estará perpetuando a ideia de que racismo é um tema pertinente apenas para não brancos e reproduzir o racismo em atitudes individuais e institucionais, como, por exemplo, não identificar uma prática racista advinda de si ou de um estagiário. 0 supervisor poderá traçar estratégias para conhecer em que ponto está o processo de construção da identidade racial dos estagiários e criar modos de tratar disso em grupo. Revelar a si mesmo de forma sincera pode ser um caminho inicial, pois pode servir de estímulo para o restante. É preciso que a supervisão seja um espaço aberto e seguro para explorar as próprias vivências, mais do que discutir teoricamente sobre relações raciais, embora isso também tenha sua importância. É preciso ser compreensivo e cuidadoso ao explorar o processo singular de construção da identidade racial de cada estagiário, para não tornar 0 ambiente potencialmente defensivo. Para que tudo isso possa acontecer, é importante que 0 supervisor busque parcerias, mesmo que informais, pois certificar-se de que há uma rede de colegas com preocupações semelhantes torna-se um suporte fundamental em situações delicadas e desafiadoras.

Por fim, é preciso compreender que o antirracismo é um aprendizado a ser desenvolvido ao longo da vida, pois não é possível alcançar uma estabilidade enquanto o racismo continuar sendo atualizado. Metaforicamente, é como se 0 antirracismo fosse um caminho interminável. Portanto, mais importante do que estabelecer um ponto de chegada, é propiciar condições para que ninguém pare de caminhar.

\section{Referências}

Almeida, S. L. de. (2018). O que é racismo estrutural? Belo Horizonte: Letramento.

Bento, M. A. \& Carone, I (Orgs.). (2002). Psicologia Social do Racismo (2a. ed.). São Paulo: Vozes.

Bicudo, V. L. (1947). Atitudes raciais de pretos e mulatos em São Paulo. Sociologia. Revista Didática e Científica. Escola Livre de Sociologia e Política, 9(3), 195-219.

Brasil. Ministério da Saúde. (2016). Painel de indicadores do SUS no 10: Temático saúde da população negra Vol. VII. Brasília, DF: Ministério da Saúde.

Cintra, M. S.\& Bernardo, M. H. (2017). Atuação do psicólogo na Atenção Básica do SUS e a Psicologia Social. Psicol. cienc. prof., 37 (04), 883-896. https:// doi.org/10.1590/1982-3703000832017

Corbella, S. \& Botella, L. (2004). Investigación en psicoterapia: proceso, resultado y factores comunes. Madrid: Editorial Vision Net.

Corbella, S. (2019). El Estilo Personal del Terapeuta y la Alianza Terapéutica. In: Fernández-Álvarez, H. \& García, F. (Eds.), El Estilo Personal del Terapeuta (pp. 57-90). Buenos Aires, Argentina: Editorial Polemos.

Conselho Federal de Psicologia (2002). Resolução (FP no 018/2002. Recuperado de http://site.cfp.org.br/wpcontent/uploads/2002/12/ resoluca02002_18.PDF

Diangelo, Robin J. (2018). Não basta não ser racista: sejamos antirracistas. São Paulo: Faro Editorial.

Frankenberg, R. (2004). A miragem de uma Branquitude não marcada. In V. Ware (Org.), Branquidade, identidade branca e multiculturalismo. (pp. 307-338). Rio de Janeiro: Garamond.

Gamst, G., Aguilar-Kitibutr A., Herdina, A., Hibbs, S., Krishtal, E., Lee, R., Martenson L. (2003). Effects of racial match on Asian American mental health consumer satisfaction. Mental Health Services Research, 5(4), 197-208. https://doi.org/10.1023/A:1026224901243

Gomes, I. (2019). Reflexão sobre os limites e possibilidades de empatia na escuta de mulheres negras. In: M. Tassinari, M. \& W. Durange, (Orgs.). Empatia: a capacidade de dar luz à dignidade humana. (pp. 85-101). Curitiba: CRV.

Gouveia, M. \& Zanello, V. (2018). Saúde mental e racismo contra negros: Produção bibliográfica brasileira dos últimos quinze anos. Psicologia: Ciência e Profissão, 38(3), 450-464. https://doi.org/10.1590/198237030003262017

Grosfoguel, R. (2020). Para uma visão decolonial da crise civilizatória e dos paradigmas de esquerda ocidentalizada. In J. Bernardino-Costa, N. Maldonado-Torres \& R. Grosfoguel, (Orgs). Decolonialidade e pensamento afrodiaspórico (pp. 55- 78). Belo Horizonte: Autêntica.

Hooks, B. (2013). Ensinando a transgredir: a educação como prática da liberdade. Sâo Paulo: Editora WMF Martins Fontes.

IBGE. Instituto Brasileiro de Geografia e Estatística. (2020). Características gerais dos domicílios e dos moradores 2019. Informativo PNAD Contínua. Atualização 05.05.2020. https://biblioteca.ibge.gov.br/visualizacao/ livros/liv101707_informativo.pdf.

Kilomba, G. (2019). Memórias da plantação: episódios de racismo cotidiano Rio de Janeiro: Cobogó.

Meyer, 0. L., \& Zane, N. (2013). The influence of race and ethnicity in clients' experiences of mental health treatment. Journal of Community Psychology, 41(7), 884-901. https://doi.org/10.1002/jcop.21580

Mignolo, W. (2014). Desafios Decoloniais hoje. In M. E. Borsani \& P. Quintero (Orgs.). Los desafios decoloniales de nuestros días: pensar en colectivo. 1a ed. Neuquén: EDUCO - Universidad Nacional del Comahue,

Moreira, V. \& Torres, R.B. (2013). Empatia e redução fenomenológica: possível contribuição ao pensamento de Rogers. Arquivos Brasileiros de Psicologia, 65(2), 181-197. Recuperado de http://pepsic.bvsalud.org/scielo.php?script=sci_arttext\&pid=\$1809-52672013000200003\&lng=pt\&tlng=pt. 
Rogers, C. (1985). Tornar-se pessoa. São Paulo: Martins Fontes.

Sacco, A. M., Couto, M. C. P. P., \& Koller, S. H. (2016). Revisão sistemática de estudos da psicologia brasileira sobre preconceito racial. Temas em Psicologia, 24(1), 233-250. https://doi.org/10.9788/TP2016.1-16

Schucman, L.V. (2020). Entre o encardido, o branco e o branquíssimo. Branquitude, hierarquia e poder na cidade de São Paulo. São Paulo: Veneta.

Souza, N. S. (1990). Tornar-se negro. Rio de Janeiro, RJ: Graal.

Sue, D. W., Sue, D, Neville, H. A. \& Smith, L. (2019). Counseling the culturally diverse: Theory and practice. (8th ed.) New York: Wiley.

Tavares, J.S.C. \& Kuratani, S.M.A. (2019). Manejo Clínico das Repercussões do Racismo entre Mulheres que se "Tornaram Negras". Psicologia: Ciência e Profissão, 39, e184764, 1-13. https://doi.org/10.1590/19823703003184764

Ward, E. C. (2005). Keeping It Real: A Grounded Theory Study of African American Clients Engaging in Counseling at a Community Mental Health Agency. Journal of Counseling Psychology, 52(4), 471-481. https://doi. org/10.1037/0022-0167.52.4.471

Wood, J.K. (Org.) et al. (1994). Abordagem Centrada na Pessoa. Vitória: Editora Fundação Ceciliano Abel de Almeida. 